\title{
A Legal Analysis of the Precedents of Medical Disputes in the Cosmetic Surgery Field
}

\author{
Bo Young Park, Min Ji Kim, So Ra Kang, Seung Eun Hong \\ Department of Plastic and Reconstructive Surgery, Ewha Womans University Mokdong Hospital, Ewha Womans University School of \\ Medicine, Seoul, Korea
}

Background Disputes regarding medical malpractice occur between practitioners and patients. As patients have become increasingly aware regarding medical care, an increase in the unexpected side effects of procedures has been observed, thereby leading to an increase in disputes regarding medical malpractice. In this study, we reviewed trends in precedents involving cosmetic surgery-related medical disputes, with the goal of helping to prevent unnecessary disputes in the future.

Methods We conducted a search of the judgments made in South Korean courts between 2000 and 2013 that were related to the field of plastic surgery. A total of 54 judgments were analyzed, and the selected precedents were reviewed and classified according to the kind of negligence involved.

Results The claim amounts ranged from under 8 million KRW (6,991 USD) to 750 million KRW (629,995 USD). The most common ratio of the judgment amount to the claim amount was 20\%-30\%. The judgments were classified according to the following categories: violation of the duty of explanation in 17 cases (29\%), violation of the duty of care in 10 cases (17\%), violation of both duties in 20 cases (35\%), and no violation of duty in six cases (10\%).

Conclusions Cosmetic surgery-related suits require different approaches than general malpractice suits. The Supreme Court requires plastic surgeons to determine the type, timing, methods, and scope of their treatments when considering possible results. Therefore, practitioners should be educated on their rights and responsibilities to enable them to cope with any possible medical dispute that may arise.

Keywords: Surgery, plastic / Malpractice / Medical errors / Liability, legal
Correspondence: Seung Eun Hong Department of Plastic and Reconstructive Surgery, Ewha Womans University Mokdong Hospital, Ewha Womans University School of Medicine, 1071 Anyangcheon-ro, Yangcheon-gu, Seoul 07985, Korea

Tel: +82-2-2650-5149

Fax: +82-2-3410-0036

E-mail: monkeyhong@hanmail.net

Received: 9 Nov $2015 \bullet$ Revised: 18 Feb 2016• Accepted: 1 Mar 2016

pISSN: 2234-6163 • elSSN: 2234-6171 • http://dx.doi.org/10.5999/aps.2016.43.3.278• Arch Plast Surg 2016;43:278-283

We would like to sincerely and profusely thank all of our staff at Ewha Womans University Mokdong Hospital for their able guidance and support in completing this project.

No potential conflict of interest relevant to this article was reported.

\section{INTRODUCTION}

Demand for cosmetic surgery has dramatically increased in recent years due to people's desire to beautify themselves, the development of improved medical techniques, increased living standards, and a globalized social trend of valuing appearance.
As a result, a domain of healthcare with the sole purpose of aesthetic improvement and not the treatment of disease is now recognized as a field of medicine. Moreover, the variety of cosmetic surgery procedures has increased, extending to involve the entire body. The demand for cosmetic surgery in Korea has been overwhelming, as evidenced by the report of the International 
Society of Cosmetic Surgery in 2011, which placed the country in seventh place globally for the number of total cosmetic operations performed (at 649,938) and in first place for the number of operations per 10,000 people [1]. According to data published at the end of 2013, the number of specialists involved in plastic surgery in Korea grew to 1,855, of whom 1,245 (67.1\%) were directly involved in the cosmetic surgery business $[2,3]$.

Cosmetic surgery is performed with the goal of the personal aesthetic satisfaction of people who are otherwise of normal appearance and function. It is distinct from medically indicated surgery and is not as urgent as treatments in health care in general or in reconstructive surgery, which are mainly aimed at treating disease. Consequently, cosmetic surgery often leads to disputes despite its relatively lower invasiveness in comparison with general surgery. Therefore, it is necessary to investigate cosmetic surgery malpractice disputes using different criteria than general medical litigation.

Despite the quantitative growth of the cosmetic surgery market in Korea and the concomitant increase in postoperative adverse reactions, cases involving sequelae, and related medical disputes, no authoritative studies or statistics in this domain have been published [4]. Therefore, the present study is intended to help increase the understanding of the current situation regarding legal disputes involving cosmetic surgery in Korea through an analysis of jurisdictional precedents in cosmetic surgery-related medical disputes. Our goal is to draw attention to medical accidents caused by cosmetic surgery by investigating the legal criteria for judgments, to suggest reference points that will be helpful in preventing medical disputes, and to provide valuable information for clinical practitioners.

\section{METHODS}

\section{Selection of judgments}

Since damage claim suits dealing with medical accidents are classified separately from other damage claim suits, it is possible to evaluate medical accidents in their entirety. The present study targeted accessible judgment data from the lower courts, instead of seeking to include all cosmetic surgery-related judgments in the Korean courts. The data used for analysis came from 54 precedents in cosmetic surgery-related civil judgments for which the full texts of judgments could be obtained, but total of 58 cases were analyzed because some precedents contained multiple plaintiffs. The judgments were made in the district courts of Korea between 2000 and 2013.

\section{Database establishment}

Cases and reference data of related papers were collected using the search terms of aesthetic plastic surgery, cosmetic surgery, and plastic surgery in legal portal sites (Supreme Court legal information service [glaw.scourt.go.kr], as well as LAWnB [www. lawnb.com]), and Google Scholar. A total of 54 precedents for which the full texts of the judgments were obtained through an application to the Supreme Court of Korea and the lower courts were used to collect the raw data. Since damage suits by medical accidents are classified as accidents of compensation, it was possible to ascertain the overall number of medical accidents through examining accidents involving compensation for damages.

On the basis of the collected data described above, an analysis was performed focusing on the distribution of medical litigation cases in cosmetic surgery areas by year and type, the causes of the medical disputes, the claim amount for damages and the corresponding judgment amount, the presence or absence of medical malpractice, and the cause for judgments made against plastic surgeons.

\section{Statistical analysis}

The final sentence of precedents as a variable in statistics was restricted randomized control, we therefore employed a post-hoc analysis. The Kruskal-Wallis test was used to assess differences among the judgments finding no violation, those finding a violation of the duty of care or explanation, and those finding a violation of the duty of care and explanation. Pairwise comparisons among these groups were performed using the Mann-Whitney $\mathrm{U}$ test with the Bonferroni adjustment, and $\mathrm{P}$-values $<0.05$ were considered to indicate statistical significance.

\section{RESULTS}

The results of an analysis of 58 cosmetic surgery-related civil cases in the district courts of Korea from 2000 to 2013 for which the full texts of the judgments were available are presented below.

\section{Fig. 1. Yearly distribution of plastic surgery cases}

The number of cosmetic surgery-related precedents in 2013 was three times higher than in 2000, indicating a tendency for such cases to increase in frequency.

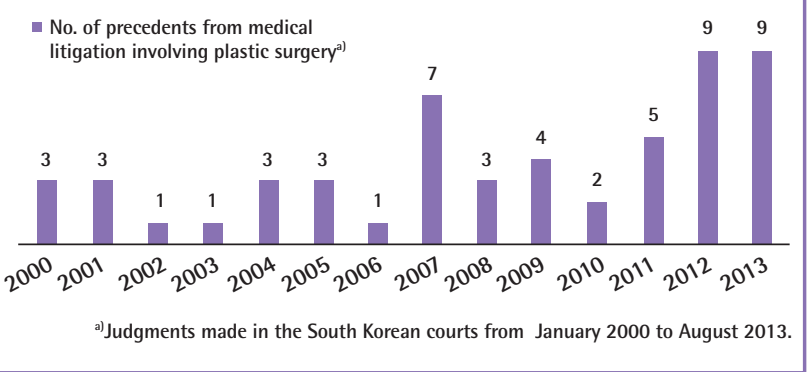




\section{Analysis of precedents}

The quantity of cosmetic surgery-related precedents increased over time (Fig. 1). Seoul was the most frequently involved jurisdiction, represented by 34 precedents (62.96\%) (Fig. 2).

The distribution of surgical sites in the cosmetic surgery-related precedents that were subjected to analysis was as follows: the face in 43 cases (70\%), the breast in 12 cases (19\%), and the extremities in even cases (11\%) (Fig. 3). Since some cases involved more than one operation or procedure being performed on the same occasion, the total number of procedures was 67 cases, which exceeded the total number of cases (58 cases) (Fig. 4). The claim amount ranged from under 8 million KRW $(6,991$ USD) to 750 million KRW (629,995 USD) (mean: 93,071,708 KRW [77,624 USD]) (Fig. 5). Since some cases involved multiple plaintiffs, the number of cases listed under claim amounts ( 58 cases) exceeded the total number of precedents ( 54 precedents).

Fig. 2. Geographic distribution of cosmetic surgery-related cases

Seoul was the most common location for cosmetic surgery-related cases.

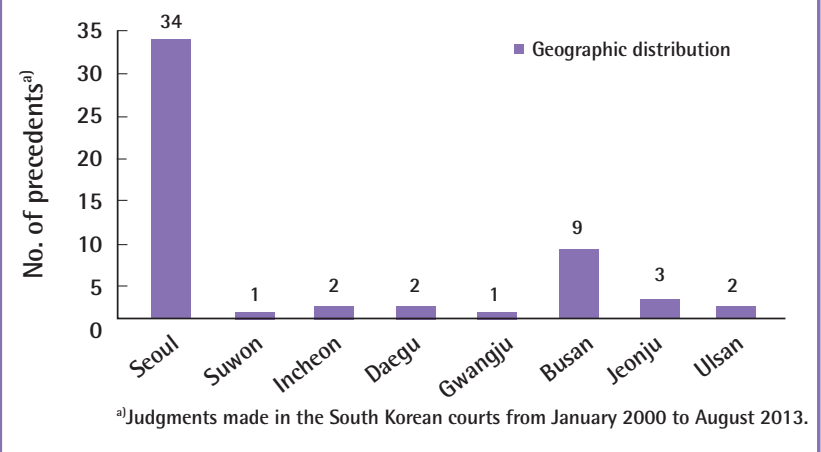

\section{Fig. 3. Distribution of surgical sites}

The areas with the most lesions were the face (43 cases, 70\%), breast (12 cases, 19\%), and extremities (7 cases, 11\%). Percentages reflect the proportion of such cases among the precedents included in this study: the South Korean courts from January 2000 to August 2013.

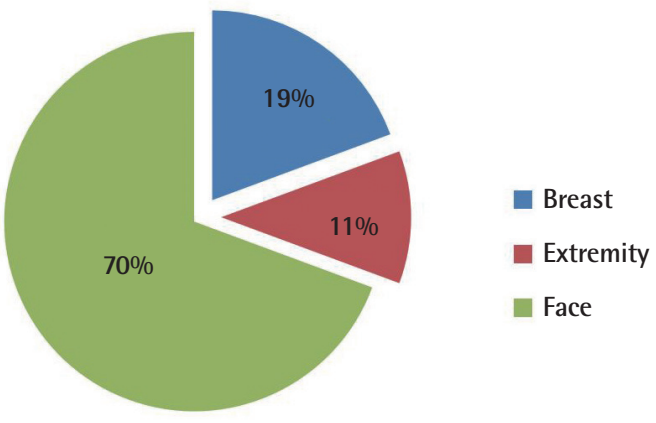

\section{Fig. 4. Distribution of surgical procedures on the face}

The most common procedure in plastic surgery-related precedents was the liposuction and fat injection (27\%), followed by nose surgery (21\%), operations on the mandible and zygoma (19\%), and the eye $(18 \%)$. Percentages reflect the proportion of such cases among the precedents included in this study: the South Korean courts from January 2000 to August 2013.

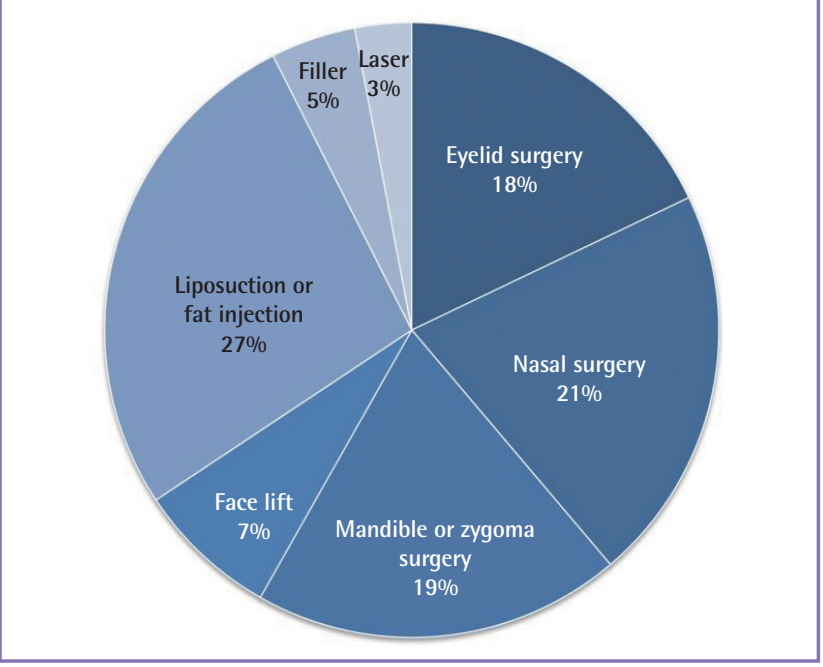

\section{Fig. 5. Damage claim amounts}

The claim amounts ranged from under 8 million KRW (6,991 USD) to 750 million KRW (629,995 USD).

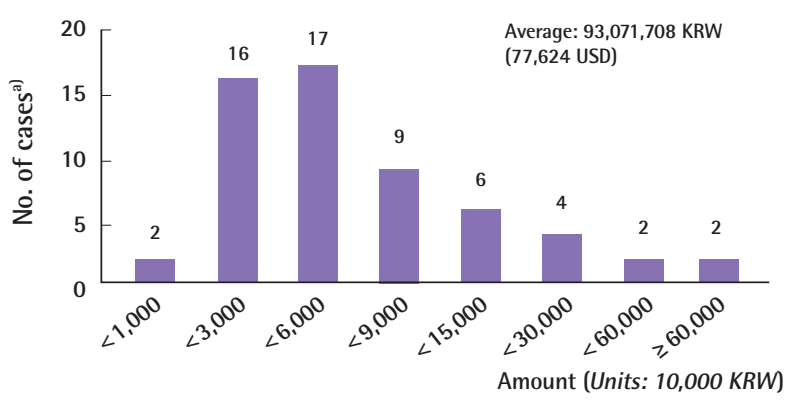

a) Cases judged by district courts of Korea from January 2000 to August 2013.

Fig. 6. Amounts awarded in judgments for damages

Most cases included fell into the range from 5 million KRW $(4,074$ USD) to 10 million KRW (81,499 USD).

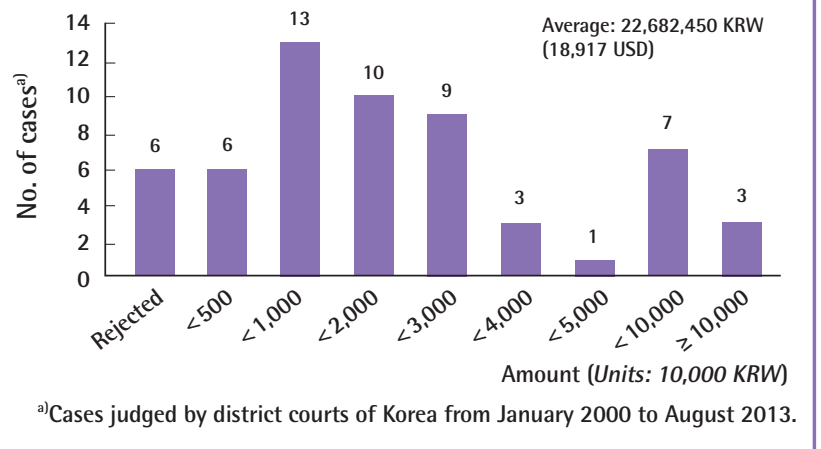


Table 1. Statistical analysis of the amount of the claims and judgement, the ratio thereof, and differences according to the violation of duty

\begin{tabular}{|c|c|c|c|}
\hline Variable & $\begin{array}{c}\text { Group } 0 \text { (no violation) } \\
(n=6)^{a)}\end{array}$ & $\begin{array}{l}\text { Group } 1 \text { (one violation) } \\
(\mathrm{n}=27)^{\mathrm{a})}\end{array}$ & $\begin{array}{l}\text { Group } 2 \text { (two violations) } \\
\qquad(\mathrm{n}=20)^{\mathrm{a})}\end{array}$ \\
\hline Ratio of judgement to claim,c) & 0 & $0.2(0.12,0.36)^{d)}$ & $0.3(0.20,0.42)^{e)}$ \\
\hline Difference of judgment and claim ${ }^{c, 1}$ & $-3,070(-6,275,-2,000)$ & $-4,498(-5,600,-1,517)$ & $-3,279(-12,070,-1,914)$ \\
\hline Judgement amount $\mathrm{t}^{\mathrm{b}, \mathrm{c}}$ & 0 & $750(500,2,971)^{d)}$ & $1,462(832,2,951)^{d)}$ \\
\hline Claim amountc) & $3,070(2,000,6,275)$ & $6,000(2,235,7,989)$ & $5,281(2,972,15,557)$ \\
\hline
\end{tabular}

a) Five cases of medical malpractice with an unknown violation of the duty of explanation were excluded from this analysis (a total of 53 cases judged in the district courts of

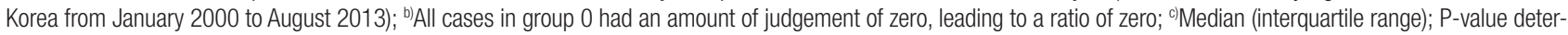

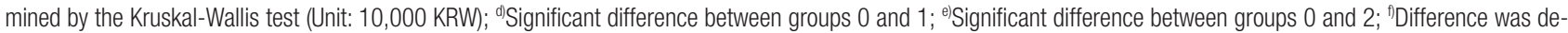
fined as the amount of the judgement minus the amount of the claim.

\section{Fig. 7. Ratio for judgment-to-claim amount}

The most common ratio for judgment-to-claim amount was 20\%$30 \%$, followed by $10 \%-20 \%$ and $30 \%-40 \%$.

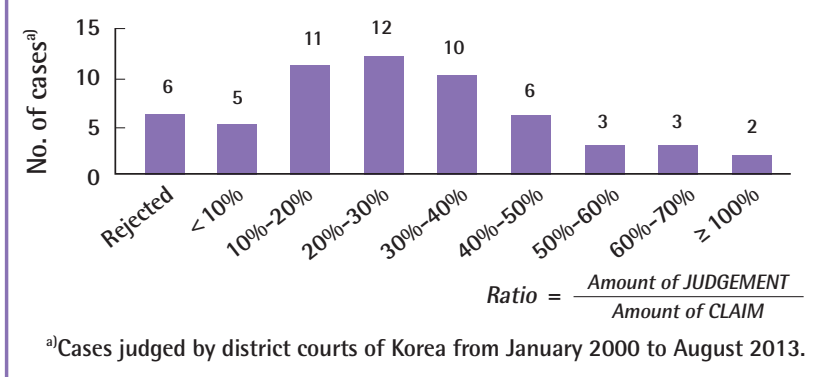

The mean amount awarded in judgments for cosmetic surgeryrelated precedents was 22,682,450 KRW (18,917 USD) (Fig. $6)$. The most common ratio of the judgment-to-claim amount was $20 \%-30 \%$, followed by $10 \%-20 \%$ (Fig. 7 ).

A violation of the duty of explanation was found in 17 cases (29\%), a violation of the duty of care was found in 10 cases (17\%), a violation of both duties was found in 20 cases (35\%), and no violation of duty was found in six cases (10\%). Five remaining cases contained no distinguishable violation of duty, and these cases were excluded from the statistical analysis (Fig. 8).

\section{Statistical analysis of the ratio of the judgment-to-claim amount depending on the violation of duty}

Post-hoc analysis was performed using the Kruskal-Wallis test and comparison among groups was performed the Mann-Whitney test with the Bonferroni correction. Statistically significant differences were found in the ratio of the judgment amount to the claim amount and the amount of the judgement. In particular, a significant difference was observed between the judgments in which no violation of either the duty of explanation or the duty of care was found and judgments in which a violation of either duty was found; however, no significant difference was found between the judgments in which one of those duties was violat-

\section{Fig. 8. Analysis of the violations of duties}

The judgments can be classified according to the type of violation of duty: duty of explanation (17 cases, 29\%), duty of care (10 cases, $17 \%)$, both explanation and care duties (20 cases, 35\%), and no violation of duty (six cases, 10\%). In five cases, the violation of duty was uncertain, and such cases were excluded from the analysis. Percentages reflect the proportion of such cases among the precedents included in this study: the South Korean courts from January 2000 to August 2013.

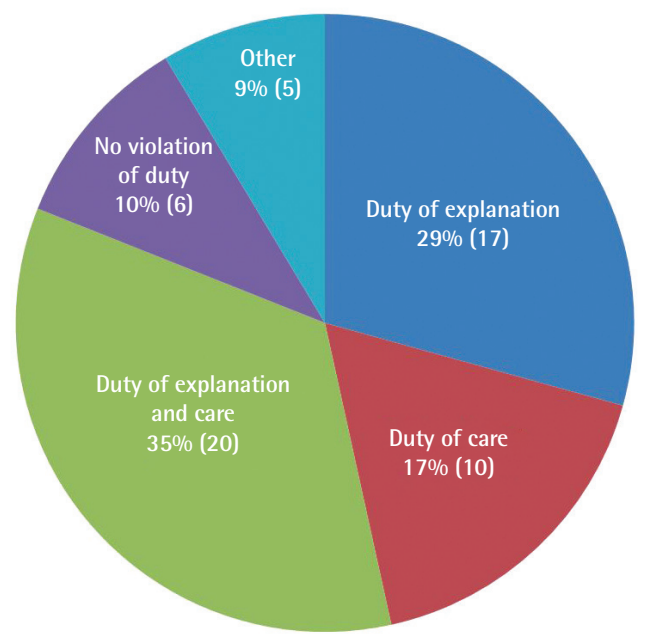

ed and judgments in which both were found to be violated (Table 1). When no attributable reason was provided by the plastic surgeon, judgments were made against the plaintiffs (patients) in compensation-for-damages cases, and when fewer attributable reasons were provided by the plastic surgeon, lower judgment amounts were decided relative to the plaintiffs' claim amount.

\section{DISCUSSION}

In the past, most legal disputes have been due to death or serious sequelae following surgery, whereas recently, an increasing number of legal disputes are due to personal dissatisfaction, such as a complaint over a small cosmetic procedure. According to Korea Consumer Agency statistics, plastic surgery-related medi- 
cal disputes have increased concomitantly with the quantitative growth in cosmetic surgery [5]. These phenomena are closely related to the fact that patients have been made more aware of their rights by the commercialization of healthcare supply systems and the expansion of the media. Nevertheless, patients may lack an understanding of medical practice, leading to unrealistic expectations regarding outcomes. In addition, plastic surgeons may also lack an understanding of the principles of medical law. Thus, when a problem between a provider and a patient arises, surgeons generally do not try to resolve it with a dialogue between the corresponding parties, but instead tend to depend on the courts $[6,7]$.

A malpractice suit is a suit where a patient claims that he or she is due damage as a result of medical malpractice occurring during the process of treatment and therefore seeks compensation. General medical treatment has the characteristics of public interest, invasiveness, a lifesaving nature, professionalism, and uncertainty. However, because cosmetic surgery has different characteristics, it is distinct from general healthcare, meaning that cosmetic surgery-related suits require different approaches than general malpractice suits.

Cosmetic surgery is mainly focused on satisfying aesthetic needs. Exaggerated advertisements or patient solicitation activities are widely practiced due to the intense competition in this market. Since the range of medical procedures and surgical methods are usually fully agreed on with the patients, plastic surgeons are bound by that agreement, which is different from typical medical practice, where a broad discretion for healthcare providers is accepted in relation to a detailed range of medical procedures. Therefore, this study investigated the characteristics of legal disputes in the cosmetic surgery field and the judgments made by the justice department.

A violation of the duty of care was found in 10 cases (19\%), a violation of the duty of explanation was found in 17 cases (32\%), and a violation of both duties was found in 20 cases (37\%). The mean claim amount was 93,071,708 KRW (77,624 USD), whereas the mean judgment amount was $22,682,450 \mathrm{KRW}(18,917$ USD). The ratio of the judgment amount to the claim amount was less than $30 \%$ in $13 \%$ of the cases, less than $20 \%$ in $10 \%$ of the cases, and between $30 \%$ and $40 \%$ in $9 \%$ of the cases. The entire claim amount was accepted only in two cases. The ratio of the judgment amount to the claim amount depended on the level of violation of duty by plastic surgeons. When both the duties of care and explanation that were expected of plastic surgeons were violated, the ratio of the judgment amount to the claim amount was relatively higher, whereas when only one duty was violated or no violation took place, the ratio of the judgment amount to the claim amount was lower. In addition, the ratio of the judgment amount to the claim amount appeared to be lower in situations where the responsibilities of the plastic surgeon were limited, such as cases where the patients also had responsibilities for the deterioration in the situation, or where bad outcomes were inevitable despite the violation of a duty.

Cosmetic surgery has different characteristics than traditional medical practice, since many cases of cosmetic surgery involve no urgency or medical indications. Therefore, plastic surgeons need to be careful not to ignore physiological and functional disorders in patients, and they have a duty to reject or stop the cosmetic surgery if there is a high probability of complications [6]. This is a duty of plastic surgeons that is stipulated in detail. In some cases, the violation of the duty of care by plastic surgeons can be clearly discerned medically. However, even when medical malpractice is not obvious, in some cases the burden of proof was shifted onto the patient due to the casual nature of the medical malpractice, and a violation of the duty of care was found. In these cases, if healthcare professionals cannot prove that no medical malpractice took place, they are not free from liability. In addition, violations of the duty of explanation have been recognized in many cases as involving a duty of care violation. In many incidents, judgments have been made against medical staff because they failed to explain any expected negative outcomes that might arise before the operation. Since consumers have a greater sense of rights, patients, as healthcare consumers, want to know about the methods used in the overall procedures in detail, and want to participate in the decision-making process. When doctors treat patients, they must fully explain the treatment, and the patients should be able to make a decision regarding their own treatment based on that explanation. However, plastic surgeons performing cosmetic surgery make decisions about the price of the medical procedure. Therefore, only cosmetic effects are emphasized in surgery with a cosmetic purpose, and explanations about adverse reactions may be neglected. As a result, a patient may make a decision about surgery without carefully considering all the issues. Hence, unexpected postoperative adverse reactions directly lead to legal disputes. These can occur as a result of postoperative complications, but if no preoperative explanations are provided, the plastic surgeon may have to bear responsibility even if no medical malpractice took place in the treatment itself.

The Supreme Court of Korea stipulates: "Although postoperative symptoms and postoperative adverse reactions are not so significant and just temporary in facial cosmetic surgeries, since patients may suffer from emotional distress or be impaired in outer activities during the recovery from the temporary, plastic surgeons must fully explain to patients in detail about the methods and necessities of treatments, general adverse reactions, im- 
provement states after the treatments, and possible temporary adverse reactions, enabling patients to choose whether or not to receive the medical practice in consideration of general symptoms caused by the surgeries and adverse reactions." [7]. This ruling particularly emphasizes the duty of explanation for cosmetic surgery performed on the face. Since cosmetic surgery is performed in healthy people, and the surgeons attempt to accomplish the patients' goals, they have limited discretion within the range of options agreed on with the patients. The Supreme Court of Korea also stipulates that: "Plastic surgeons must explain in detail about treatment methods and adverse reactions, enabling patients to decide if they will receive the treatments." In particular, since cosmetic surgery is not an urgent treatment, the duty of explanation must be more widely applied. Therefore, plastic surgeons should keep in mind the obligation of explanation. Ideally, it would be best to have the treating doctor explain the risks and benefits to the patient directly. To guarantee the patient's right of self-determination, the explanation must be given at a point in time when a certain diagnosis has been made. Regarding complications in aesthetic surgery, explanations must be provided if the complications, regardless of how rare, can have a substantial effect on the patient's body. No official format exists for such explanations; verbal explanations are widely accepted, although practices can vary according to the level of trust between the doctor and patient.

The most ideal resolution would be for plastic surgeons themselves to reduce preventable medical malpractice in order to prevent disputes from arising. However, it is impossible to remove the fundamental causes of disputes regarding cosmetic surgery because the outcomes are particularly likely to be assessed according to the patient's subjective evaluation. However, considering that patients with unsatisfactory outcomes do not always engage in a full medical dispute, if healthcare professionals put efforts into reducing the discomfort of patients from the time when they start to complain about their dissatisfaction with the outcomes, they should be able to reduce the number of legal disputes. If complaining patients are left unattended, they will seek to engage with the plastic surgeons more aggressively, and as they are fully equipped with the requisite medical information, this may rapidly lead to a legal dispute. It should be remembered that a legal dispute is a process in which both patients and plastic surgeons incur numerous costs, and that legal disputes are time-consuming endeavors.

\section{REFERENCES}

1. ISAPS international survey on aesthetic/cosmetic procedure performed in 2011 [Internet]. Hanover (NH): International Society of Aesthetic Plastic Surgery; [cited 2011 May 17]. Available from: http://www.isaps.org/news/isapsglobal-statistics.

2. Kim WJ, Choi YM. Present situation and strategy of growth for medical tourism in Korea [Internet]. Seoul: KITA Institute for International Trade; 2010 [cited 2011 May 17]. Available from: http://www.kita.net/newtri2/report/iitreporter_view.jsp?pageNum $=1 \& \mathrm{nGubun}=3 \&$ s_con $=\&$ s_text $=\&$ $\mathrm{sStartDt}=\& \mathrm{sEndDt}=\& \mathrm{~s}$ Order $=\& \mathrm{~s}$ Classification $=\&$ actionN ame $=\& s N_{0}=773$.

3. Korea Consumer Agency. Annual report and casebook on consumer remedy damage. Seoul: Korea Consumer Agency; 2011.

4. Ryu JE, Suh IS, Seo KH, et al. The expectation and satisfaction of college women on aesthetic surgery. J Korean Soc Aesthetic Plast Surg 2002;8:159-68.

5. Kim KH, Choi JW, Lee ES. The state of medical malpractice caused by private practice physicians (2010-2012): analysis through incident reports at Korean Medical Association Medical Indemnities Mutuals. J Korean Med Assoc 2015;58:33648.

6. Cho HS, Lee SH, Shon MS, et al. Reasons why patients and families choose medical dispute. J Korean Acad Fam Med 1998;19:274-91.

7. You H. Civil liability for medical malpractice.J Korean Med Assoc 2013;56:648-54. 